\title{
GROSS AND HISTOMORPHOLOGICAL STUDIES OF THE OVIDUCT OF NATIVE CHICKEN OF BANGLADESH
}

\author{
D. Mishra ${ }^{1}$, N. Sultana ${ }^{2}$, M. A. Masum ${ }^{2}$ and S. Rahman \\ Department of Surgery and Obstetrics and ${ }^{2}$ Department of Anatomy and Histology, Faculty of Veterinary \\ Science, Bangladesh Agricultural University, Mymensingh-2202, Bangladesh
}

\begin{abstract}
The present study was carried out on the oviduct of laying native chicken of Bangladesh at the age range of 8-12 months old. After dissection, morphological parameters such as total length and weight of oviduct, length and weight at the age range of 8-11 months were determined. For the histological study, after preparation and staining with hematoxylin and eosin, histological layer of oviductal tissues were recognized. The mean length and weight of total oviduct of native chicken were $7.18 \pm 4.22 \mathrm{~cm}$ and $24.45 \pm 1.81 \mathrm{gm}$ respectively. The mean length and weight of oviductal segments, infundibulum (7.18 \pm $4.22 \mathrm{~cm}$ and $7.18 \pm 4.22 \mathrm{gm})$, magnum $(18.40 \pm 6.75 \mathrm{~cm}$ and $18.40 \pm 6.75 \mathrm{gm})$, isthmus $(7.68 \pm 3.46 \mathrm{~cm}$ and $7.68 \pm 3.46 \mathrm{gm})$, uterus $(6.10 \pm 2.80 \mathrm{~cm}$ and $6.10 \pm 2.80 \mathrm{gm})$ and vagina $(6.83 \pm 2.82 \mathrm{~cm}$ and $6.83 \pm 2.82 \mathrm{gm})$ were measured. Both the length and weight of oviductal segment was progressively increasing from 8-10 months and was decreased at 11 months age. Histological features of oviductal segments varied in regards to the distribution of gland, connective tissues arrangement and mucosal folding. Particularly, the distribution of tubular glands among the segments of oviduct was significantly different. In the magnum and isthmus, populations of tubular glands were higher whereas other segments had limited glands.
\end{abstract}

Key words: Chicken, Oviduct, Gorss morphological study

\section{INTRODUCTION}

Chickens of Bangladesh are mostly indigenous type called deshi chicken and their body weight ranging from 1.0 to $1.4 \mathrm{~kg}$. Reproduction in poultry is completely different from other farm animal species. In the poultry, there are two principle reproductive organs; ovary and oviduct; which are participated in the production of egg in laying hen. The oviduct of chicken is an egg producing organ, which convey the ovum to the cloaca and it successively adds the albumin from the glands of magnum. Finally, shell membrane added from isthmus, the hard calcite shells and shell pigments from uterus and the bloom or cuticle from the gland of vagina. Therefore, oviduct play vital role in the assembly of egg components after receiving ova from ovary. From the available literature it is observed that the anatomical study of oviduct was confirmed in hybrid chicken (Khan et al., 1999). In deshi chicken developmental study of the oviduct was done by Istam et al. (2002), but research has not been carried out regarding the adult deshi chicken. Therefore, the present work has been carried to study on gross and histomorphological analysis of the adult deshi chicken.

\section{MATERIALS AND METHODS}

The present study was conducted in the Department of Anatomy and Histology; and Department of Surgery and Obstetrics, Bangladesh Agricultural University, Mymensingh during the period from January 2011 to May 2011.

\section{Chickens}

Adult female chickens of local breed (called native or deshi chicken- Gallus domesticus, $\mathrm{n}=4$ ) were used. These chickens were purchased from the village farmers close to the Bangladesh Agricultural University, Mymensingh. These adult deshi chickens were selected from age 8 to 11 months old. The age of deshi chicken was estimated based on the farmers' informations. The oviducts which were free from gross pathological disorder were only used for both morphometrical and histological studies.

Present Address: ${ }^{1}$ Senior Extension Officer, Sujal Dairy Private Ltd. Kaski pokhara, Nepal

*Corresponding e-mail address: vetmishra209@gmail.com

Copyright ( 2014 Bangladesh Society for Veterinary Medicine 


\section{Mishra and others}

\section{Gorss morphological study of oviduct}

In this study, deshi chickens were killed by cervical subluxation. Standard anatomical dissection of each bird was done as described previously. Total four deshi chickens were used from 8, 9, 10, 11 months of age (one from each month). The whole oviduct was quickly dissected out and stretched on tray. The morphometrical study included the color, length and weight of oviduct. Individual weight of each segment of oviduct was measured by balance weight machine. Length was measured by scale. Relative weights of the oviduct were also calculated adopting following formula according to Federova (1987).

$$
\text { Relative weight of the oviduct }=\frac{\text { Weight of the oviduct }}{\text { Body weight }} \times 100
$$

\section{Preparation of tissues for histomorphological study}

After collecting the oviducts, segments of the oviducts were separated. From each segment, tissues were cut into small pieces and fixed in the Bouins fluid (Gridly, 1960) for 24 hours. After fixation, the samples were dehydrated in the series of ascending grade of alcohol (70\%, 80\%, 90\%, 95\%, $100 \%$ I, $100 \%$ II and $100 \%$ III) for 2-3 hours each. Followed by clearing in three changes of xylene, each for 30 minutes interval and the tissues were infiltrated with paraffin. As soon as the infiltration was completed, the tissues were embedded in paraffin and finally the embedded paraffin blocks were attached with block holder.

Tissues were sectioned at 6 micrometer thickness using sliding microtome (MIC 509, Euromex, Japan). After sectioning, the sections were floated on lukewarm water floatation bath for stretching and then the paraffin sections were mounted on slides glass using an adhesive (egg albumins) and dried 6 to 24 hours on hot plate of slide warmer boxes.

In order to study the histological structures of oviduct, tissues sections were stained with Mayers Hematoxylin and Eosin method (Gridley, 1960). Finally, slides were mounted with DPX which was kept over the tissue section and dried for 24 hours. After all these preparation of slides, photographs were taken with microscope equipped with a camera (Nikkon, Japan).

\section{Statistical analysis}

In this study, mean \pm SD of total length and weight as well as individual segment data were analyzed. Statistic was carried out using ANOVA to compare the individual segment with the total length.

\section{RESULT AND DISCUSSION \\ Morphology of the oviduct \\ General morphology of the oviduct}

In the present study, only the left oviduct was found functional as described by several authors in different poultry breed (Kar, 1947).

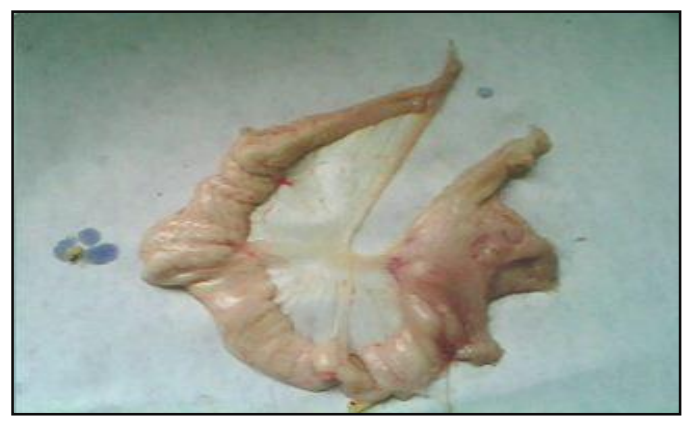

Fig. 1. Photographs of left oviduct of deshi chicken after dissection 
The left oviduct was extended from ovary to cloacae and had occupied the largest part of abdominal cavity. In the local deshi chicken of Bangladesh, oviduct was initially thin and fiber likes structure at oneday old, and highly coiled at 30 weeks. Similar result was observed in hybrid chicken (White Leghorn) at one-day old to 15 weeks old chicken by Kar (1947).

These authors showed the developmental changes in the oviduct from Day-1 to 30 weeks (5 month). In the present study, using the adult laying hen at 8-11 months old, oviduct was highly convoluted, and had clearly five segments (Fig. 1). The total length and weight of the oviduct was $46.18 \pm 9.49 \mathrm{~cm}$ and $24.45 \pm 1.81$ gm respectively (Table 1). Therefore, the present study revealed the additional information of adult deshi laying hen at 8-11 months old.

\section{Length of each segments of oviduct \\ Infundibulum}

The present study revealed that the mean length of infundibulum of oviduct at 8-11 months old deshi chicken was $7.18 \pm 4.22 \mathrm{~cm}$ (Fig. 2; Table 2). In the deshi chicken at 30 weeks (5 month), the length of infundibulum was $5.85 \mathrm{~cm}$ whereas Taylor and Hertelendy (1960) reported $9 \mathrm{~cm}$; and Romanoff and Romanoff (1949) showed 7 $\mathrm{cm}$ in laying hen. In the previously reported deshi chicken, age of the poultry was less than the present study. Therefore, length of infundibulum of oviduct increases according to the progression of age.

\section{Magnum}

In the present study, the mean length of the magnum of oviduct at 8-11 months old chicken was $18.40 \pm 6.75$ cm (Fig. 2; Table 2). The length of 30 weeks old chicken was ranged from 20 to $48 \mathrm{~cm}$ (Giersberg, 1922) and differs with the report of Taylor and Hertelendy (1960), and Romanoff and Romanoff (1949) who reported in laying hen. These differences were probably due to age and breed variation of the chicken.

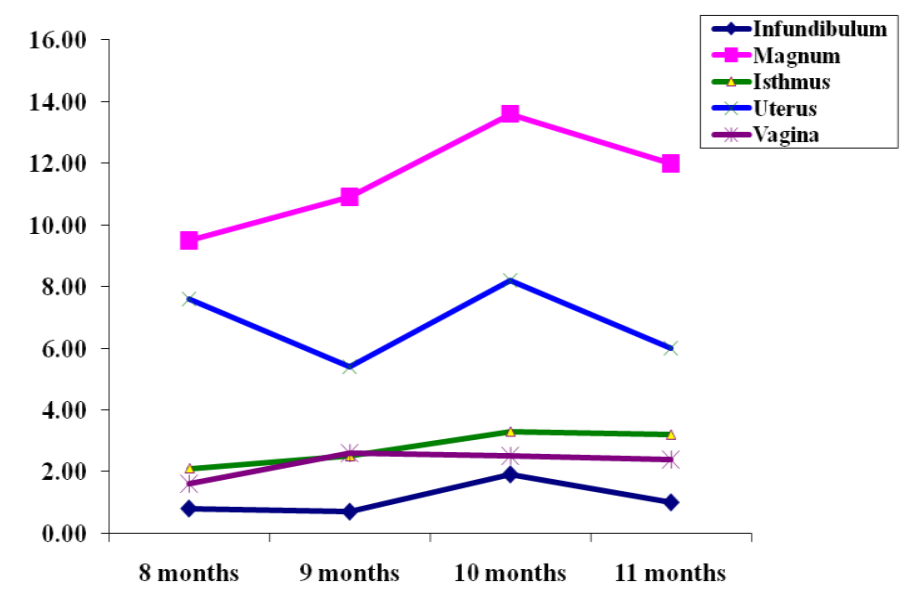

Fig. 2. Graph showing the length of different segments of the oviduct at 8, 9, 10 and 11 months of age

Table 1. Total length and weight of oviduct

\begin{tabular}{|llc|}
\hline Age groups & Total length $(\mathrm{cm})$ & Total weight $(\mathrm{gm})$ \\
\hline $\begin{array}{l}\text { Age groups ranging from } 8 \text { months to } 11 \text { month } \\
(\mathrm{n}=4)\end{array}$ & $46.18 \pm 9.49$ & $24.45 \pm 1.81$ \\
\hline
\end{tabular}




\section{Mishra and others}

Table 2. Length and weight of different segment of oviduct

\begin{tabular}{|llllll|}
\hline Parameters & Infundibulum $(\mathrm{cm})$ & Magnum $(\mathrm{cm})$ & Isthmus $(\mathrm{cm})$ & Uterus $(\mathrm{cm})$ & $\begin{array}{c}\text { Vagina } \\
(\mathrm{cm})\end{array}$ \\
\hline Length $(\mathrm{cm})$ & $7.18 \pm 4.22$ & $18.40 \pm 6.75$ & $7.68 \pm 3.46$ & $6.10 \pm 2.80$ & $6.83 \pm 2.82$ \\
Weight $(\mathrm{gm})$ & $1.10 \pm 0.548$ & $11.50 \pm 1.73$ & $2.78 \pm 0.574$ & $6.80 \pm 1.32$ & $2.28 \pm 0.457$ \\
\hline
\end{tabular}

\section{Isthmus}

The mean length of the isthmus at 8-11 months old chicken was $7.68 \pm 3.46 \mathrm{~cm}$ (Fig. 2; Table 2). The result was differed from Giersberg (1922), Taylor and Hertelendy (1960), and Romanoff and Romanoff (1949). They reported that the length of the isthmus in laying hen were 4 to 10 respectively. These variations in the length range of the present study in comparison with hybrid were due to strain differences.

\section{Uterus}

The present study revealed that the length of uterus was $6.10 \pm 2.80 \mathrm{~cm}$ (Fig. 2; Table 2). The length of magnum at 30 weeks old chicken of the present study was similar in range from 4 to $12 \mathrm{~cm}$ that was reported by Giersberg (1922) in laying hen, but it was not in agreement with the report of Taylor and Hertelendy (1960), and Romanoff and Romanoff (1949) that was $11 \mathrm{~cm}$ and $8 \mathrm{~cm}$, respectively. These authors had used hybrid chicken breed.

\section{Vagina}

The length of vagina of oviduct at $8-11$ months old chicken was $6.83 \pm 2.82 \mathrm{~cm}$ (Fig. 2; Table 2). In laying hen, the length of vagina of the present data is in agreement with the length range (4 to $12 \mathrm{~cm}$ ) that was reported by Giersberg (1922) but it was not in agreement with the report of Taylor and Hertelendy (1960), and, Romanoff and Romanoff (1949).

\section{Weight of the segments of oviduct Infundibulum}

The present investigation revealed that the weight of infundibulum of oviduct was $1.10 \pm 0.548$ gm (Fig. 3; Table 2). The weight of the infundibulum in present study was similar to previous study by Warren and Scott (1935).

\section{Magnum}

The results of the present study was $11.50 \pm 1.73$ gm (Fig. 3; Table 2). The report of the present study was inconsistent with the report of Warren and Scott (1935) where they found 17.6 gm magnum in hybrid chicken.

\section{Isthmus}

The present study revealed that the weight of isthmus was $2.78 \pm 0.574 \mathrm{gm}$ (Fig. 3; Table 2) which was differed with Warren and Scott (1935) who reported that it was $4.4 \mathrm{gm}$ because deshi chicken lay their eggs.

\section{Uterus}

The present study revealed that the weight of uterus was $6.80 \pm 1.32 \mathrm{gm}$ (Fig. 3; Table 2). It was not in agreement with report of Warren and Scott (1935) where they noticed 13.8 gm in hybrid chickens, however, they did not mention ages of chickens. This difference was probably due to strain differences and body weight of individual bird.

\section{Vagina}

The present investigation observed that the weight of vagina was $2.28 \pm 0.457 \mathrm{gm}$ (Fig. 3; Table 2). Whereas, Warren and Scott (1935) reported that the weight of vagina of laying hen was $8 \mathrm{gm}$. The lower weight of present study was due to the indigenous low egg producing breed. 


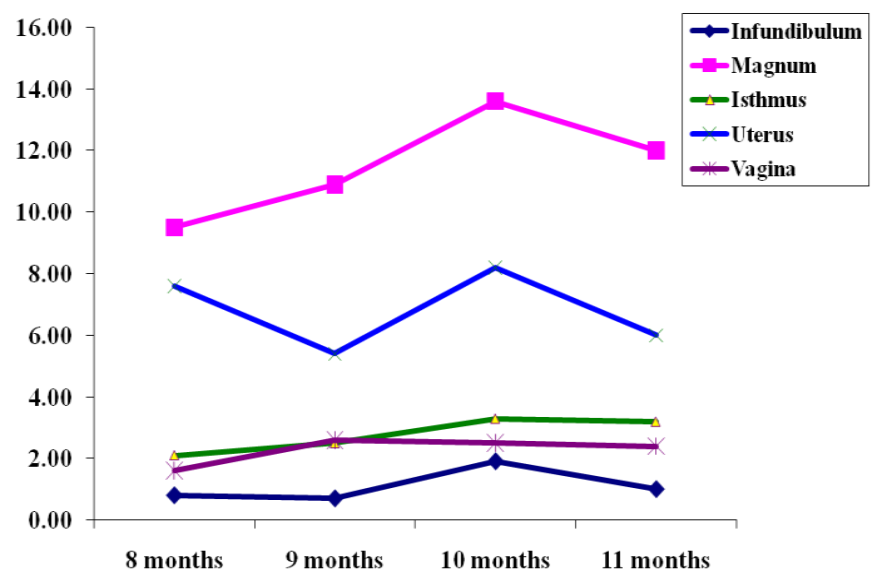

Fig. 3. Graph showing the weight of different segments of the oviduct at 8, 9, 10 and 11 months of age

\section{Histological study of oviduct}

Oviduct of laying deshi chicken had luminal epithelium, gland, connective tissues, muscle layer and outer serosa as described by several authors in different breed (Khan et al., 1999; Islam et al., 2002). However, the structure of these components varied according to the segment of oviduct in the present study.

Lamina epithelia were small to large in height depends on the segments of the oviduct (Fig. 4A-E). The lamina propria was consisted of diffused fibroblast and collagen fibers. Sub-mucosa of oviduct was continued directly with the lamina propria at all stages of postnatal development of deshi chicken until the adult age. This was followed by the tunica muscularis highly developed in adult deshi chicken. This layer was very thin at oneday old chicken, moderately developed at 12 weeks and similar results were also observed by Curtis (1910). The oviducts consisting of an outer longitudinal and an inner circular layer with connective tissues. The outer most layer of the oviduct was serosa and this was thin in the infundibulum, magnum and isthmus, developed in uterus and vagina of deshi chicken. Previously, Islam et al., (2002) reported that, the mucosal folds of laying hens were short and tongue shaped at one-day old deshi chicken. With the aging, the infundibular folds were increased in height at 12 and 19 weeks old, and become highly developed at 30 weeks of age. In contrast, the mucosal folds in the magnum and isthmus were medium sized at 12 weeks and well developed at 19 and 30 weeks old deshi chicken. On the other hand, uterine mucosal folds were dome shaped at 12, weeks, elongated at 19 and 30 weeks old deshi chicken in the uterus and vagina. The report concerning the development of mucosal folds of the oviductal segments was not observed in the available literature. In the present study, mucosal fold highly coiled and folded during 8-12 months of gestation.

\section{Infundibulum}

It is the first part of oviduct, possesses long spiral folds with few glands (Fig. 4A). At the beginning of magnum, the epithelial folds become smaller and the glandular grooves disappear before the typical broad longitudinal folds of the magnum develop. This result is similar to that of the other fowl (Richardson, 1935).

\section{Magnum}

The magnum; albumin secreting region, was lined with columnar epithelium and consists of huge number of glands (Fig. 4B). The tubular glands in the magnum are highly developed and open to the epithelial surface. This feature is similar in other fowls. Developments of this segment have been reported previously. The albumenproducing gland in the magnum was observed at 30 weeks old (Islam et al., 2002) however, Khan et al. (1999) observed these glands at 19 weeks old in White Leghorn chicken. That is why, the White Leghorn chickens were laying their eggs earlier, in comparison to our deshi chickens. In the present study, laying bird was mature enough so gland was clearly observed. This is due to strain differences. 


\section{Mishra and others}

\section{Isthmus}

It starts immediately after the magnum and have some histological similarities from magnum. Isthmus showed numerous glands for secreting of the shell membrane (Fig. 4C). Compare to the magnum, isthmus contains more glands and is in agreement with previously reported in deshi laying hen (Islam et al., 2002) and in other fowls (Madekurozawa, 2002). The glands of the isthmus and the shell gland of the uterus were also found at 19 weeks old chicken (Islam et al., 2002). These results of the present study were in agreement with Johnston et al. (1963) and Breen and Bruyn (1964).

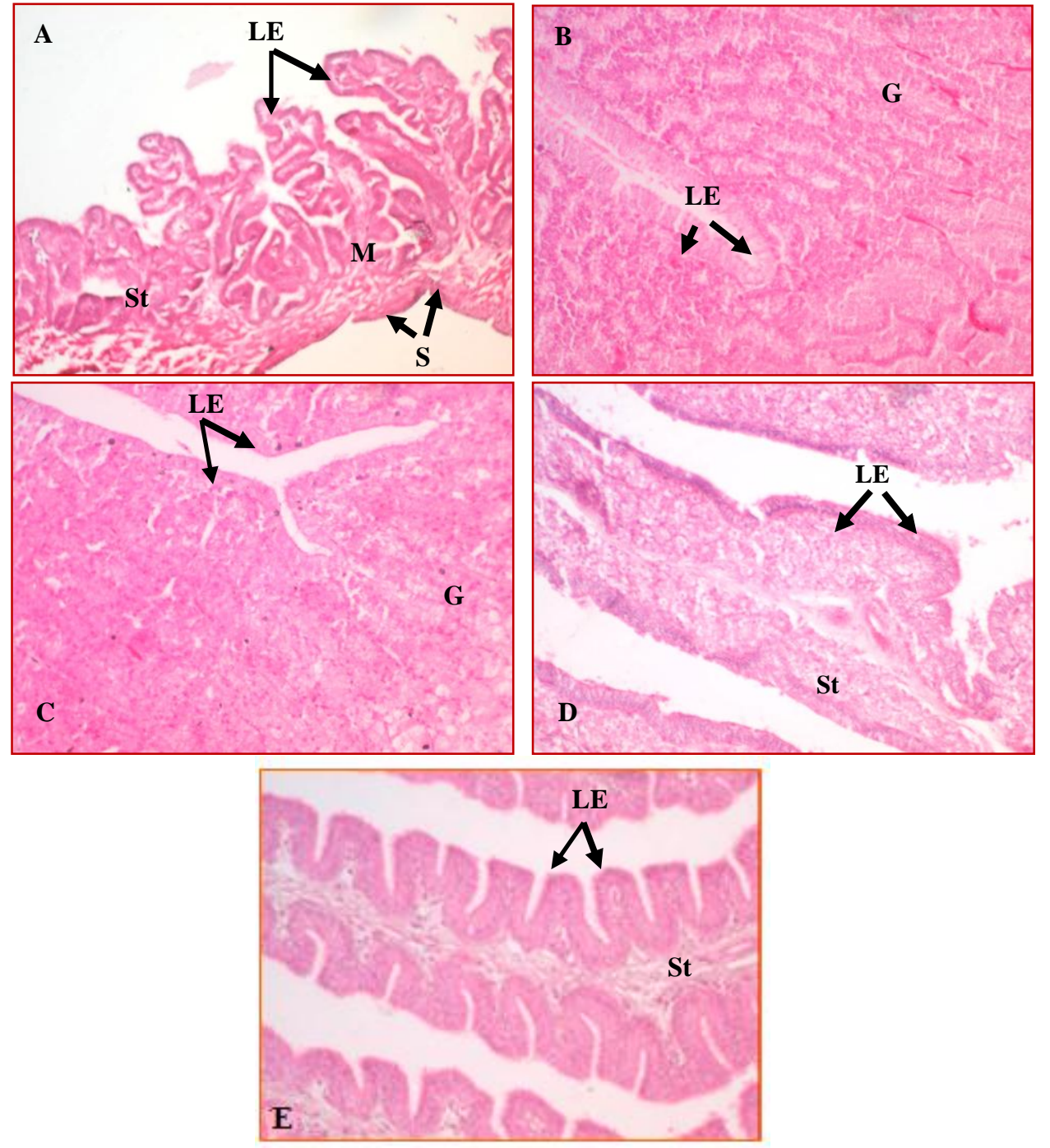

Fig. 4. Histological photographs of infundibulum (A), magnum (B), isthmus (C), uterus (D) and vagina (E) stained with Hematoxylin and Eosin. Photographs were taken at 20X objectives. LE; luminal epithelium, G; Gland, M; muscle, St; stroma, S; Serosa 
Gross and histomorphological studies of the oviduct of native chicken

\section{Uterus}

Uterus was characterized by longer and more complex mucosal folds are than the isthmian ones. Luminal epithelium was pseudostratified and is intermittently ciliated (Fig. 4D). The propria sub-mucosa contains branched tubular glands. Loose and well vascularized connective tissue is sparse between the glands. Similar observation was detected by other researcher (Johnston et al., 1963, Breen and Bruyn 1964 and Islam et al., 2002).

\section{Vagina}

The mucosa of the vagina forms longitudinal ridges or folds carrying secondary fold which are particularly regular in arrangement (Fig. 4E). Luminal epithelium of the vagina was lined by pseudostratified epithelium with columnar shaped. There was no tubular glands in the mucosal fold that seen for isthmus. Similar results were observed by Fuji (1963), in White Leghorn chicken and local deshi at postnatal development. The great part of the thickness of the vaginal wall is composed of the muscular layers. The inner circular layers are strongly developed and form the vaginal sphincter. The outer longitudinal layer is consists of bundles of muscle fibers scattered throughout a connective tissue stroma.

\section{REFERENCES}

1. Breen PC, De Bruyn PPH (1969). The fine structure of the secretory cells of the uterus (shell gland) of the chicken. Journal of Morphology 128, 35-66.

2. Curtis MR (1910). The ligaments of the oviduct of the domestic fowl, Bull. The Maine Agricultural Experiment No 176: 1-20.

3. Federova NN (1987). Growth and development of the reproductive system in white Leghorn hens in different lightly system. Sobor. Nanch. Trud. Moskovaskaya Veterinaraya Akademyia 128: 37-40.

4. Fujii S (1963). Histological and histochemical studies on the oviduct of the domestic fowl with special reference to the region of utero-vaginal juncture. Archives of Histology and Japanese 23: 447-459.

5. Giersberg H (1922). Untersuchunger uber physiologie und histologie des eileiters der reptilien und vogel: nebst einern beifpag zur faseganese. Zeitschrift fur wissenschaftliche Zoologie 120: 1-97.

6. Gridley MF (1960). Manual of histologic and special staining technique. MacGraw-Hill Book Company, USA, 28-29: 82-83.

7. Islam MR, Khan MZI, Rahaman ML and Mohsin K (2002). Postnatal growth and development of oviduct of deshi chicken (Gallus gallus domesticus) of Bangladesh. Bangladesh Veterinary Journal 36 (1-2): 35-41.

8. Johnston HS, Aitken RNC and Wyburn GM (1963). The fine structure of the uterus of the domestic fowl. Journal of Anatomy 97: 333-344.

9. Kar AB (1947). Studies on the ligaments of the oviduct in the domestic fowl. Anat. Rec. 97: 175-192.

10. Khan MZL, Asaduzzaman M, Rahman A and Islam Kh N (1999). Distribution and quantification of large granular lymphocytes (LGLs) in the sperm host glands of chicken oviduct. Bangladesh Journal of Animal Science 28(1-2): 47-51.

11. Richardson KC (1935). The secretory phenomena in the oviduct of the fowl, including the process of shell formation examined by microincineration technique. Philosophical Transactions of the Royal Society B 225: 149-195.

12. Romanoff AL and Romanoff AJ (1949). The avian Egg. John Wiley and Sons, New York.

13. Taylor T and Hertelendy F (1960). Parallel distribution of calcium and citric acid in the oviduct of the hen. Nature 187: 244-245.

14. Warren DC and Scott HM (1935). Physiological factors influencing the, rate of egg formation in the domestic hen. Journal of Agricultural Research 51: 565-572. 